\title{
Milage payments for hospital doctors
}

\author{
MICHAEL LOWE
}

At the senior hospitals conference last year the chairman of the Negotiating Subcommittee estimated that most consultants who used their cars for NHS work were losing about $£ 500$ of taxed income a year. So hospital doctors' disenchantment with their car expenses reimbursement scheme was not surprising. They saw many employers providing cars for their senior staff and could, perhaps, be forgiven for asking why the NHS could not supply a car for them or at least introduce a realistic reimbursement scheme. Discussions with the DHSS have, in fact, been in progress for several years, and in December 1980 the DHSS issued a circular ${ }^{1}$ detailing the revised structure of payments to hospital doctors for reimbursement of their motoring costs.* This represented the outcome of extensive negotiations with civil servants, discussions with Ministers, and arguments in the medical profession and between the medical profession and other Health Service employees. It is a good deal but still falls far short of providing realistic reimbursement. The total package has increased the cost of hospital doctors' transport by $34 \%$, but about half of this amount would have been necessary under the previous payments structure to take account of increases in petrol and other running costs.

Early in 1978 hospital doctors broke away from the negotiations being conducted on behalf of all Health Service employees through the General Whitley Council structure and decided to conduct their own negotiations. They believed that a special case could be made for more favourable treatment for hospital doctors; a separate deal would have been virtually impossible to negotiate in the Whitley structure. The other Health Service unions strongly resented this move. The Whitley negotiations were concluded in September 1980; the package represented an increase of $32.5 \%$. The two deals are almost identical, the main difference being the establishment of a new "essential user" category that will benefit a relatively small number of consultants.

This new category does not apply to hospital junior doctors, a fact that gave rise to some disagreement between the senior and junior medical staff negotiators taking part in the discussions. ${ }^{2}$ Two requests were made to the Minister of State for Health to extend the new category to all hospital medical staff-providing they met the stringent criteria attached to it-but to no avail. The Minister sympathised with the profession's request but accepted his civil servants' concern that such an extension would make it difficult to resist the demands of other Health Service employees to be treated in the same way.

The profession's representatives had been encouraged when the Secretary of State for Social Services had given an assurance in July 1979 that NHS doctors were entitled to reimbursement of the full costs of maintaining and running a car to the extent that they were attributable to and incurred in the course of official business. Using schedules of motoring costs regularly produced by the motoring organisations it should have been relatively easy to agree the appropriate rates. The civil servants, however, were adamant that no individual should be able to make a "profit" from the scheme irrespective of the milage travelled. To ensure that no one made a profit they repeatedly put forward figures that meant that most doctors would make a loss.

* In Scotland a similar circular, NHS 1980 (PCS) 48, was dispatched on 30 December, operative from 20 December 1980 .

\footnotetext{
British Medical Association, BMA House, Tavistock Square, London WC1H 9JP

MICHAEL LOWE, under secretary
}

Much of the argument turned on the proportion of standing charges-road fund licence, insurance, depreciation, etc-that should be reimbursed. The profession's representatives considered that it was reasonable to expect that if a doctor travelled, say, 10000 miles a year, $100 \%$ of the costs should be reimbursed and any additional milage payments over that level should cover only petrol, oil, servicing, etc. The Department of Health proposed that there should be a maximum reimbursement of $60 \%$ of standing charges on the grounds that doctors should make some contribution towards their private milage, rejecting the point that high-milage doctors would almost certainly need to have two family cars. So much for the Secretary of State's assurance. After much bargaining the figure was eventually raised to a maximum of $75 \%$ at 9000 NHS miles.

After the negotiations had been completed the profession's representatives were sent copies of a final report on milage allowances produced by the Department's Central Management Services Unit (research department). This had been "suppressed" for about four months, as it was dated August 1980, and recommended that $80 \%$ of standing charges should be reimbursed. Obviously the profession's representatives will take this into account when the rates are being reviewed. If the departmental civil servants had accepted the advice of their own experts hospital doctors would now be marginally better off and a great deal of needless negotiating time and effort could have been avoided.

The new standard milage rates effective from 1 April 1980 are set out in table I.

TABLE I-New standard milage rates

\begin{tabular}{|c|c|c|c|c|}
\hline Cars: & Up to $1000 \mathrm{cc}$ & $1001-1500 \mathrm{cc}$ & $1501-2000 \mathrm{cc}$ & Over $2000 \mathrm{cc}$ \\
\hline $\begin{array}{l}\text { Up to } 3500 \text { miles } \\
3501-9000 \text { miles } \\
\text { Over } 9000 \text { miles }\end{array}$ & $\begin{array}{r}17 \cdot 6 \mathrm{p} \\
14 \cdot 7 \mathrm{p} \\
6 \cdot 0 \mathrm{p}\end{array}$ & $\begin{array}{r}20 \cdot 0 \mathrm{p} \\
16 \cdot 6 \mathrm{p} \\
7 \cdot 6 \mathrm{p}\end{array}$ & $\begin{array}{r}24 \cdot 7 \mathrm{p} \\
20 \cdot 4 \mathrm{p} \\
8 \cdot 9 \mathrm{p}\end{array}$ & $\begin{array}{l}26 \cdot 6 \mathrm{p} \\
22 \cdot 3 \mathrm{p} \\
10 \cdot 8 \mathrm{p}\end{array}$ \\
\hline $\begin{array}{l}\text { Other motor } \\
\text { vehicles: }\end{array}$ & Up to $150 \mathrm{cc}$ & $151-244 \mathrm{cc}$ & $245-500 \mathrm{cc}$ & Over $500 \mathrm{cc}$ \\
\hline Rate per mile & $4 \cdot 8 p$ & $6 \cdot 3 p$ & $8 \cdot 6 p$ & $9 \cdot 8 p$ \\
\hline
\end{tabular}

\section{Regular or essential users}

Any hospital doctor who is required by the health authority to use his car and travel more than 3500 miles per year will now be classified as a regular user. Hospital doctors will also be classified as regular users if they travel at least $\mathbf{1 2 5 0}$ miles a year on NHS business and $(i)$ necessarily use their car on an average of three days a week or (ii) spend an average of at least half their time on such travel including the duties performed during the visits.

Under the new category of "essential" user consultants have an alternative means of qualifying as regular users, provided that they (a) travel 1250 miles a year; $(b)$ have ultimate clinical responsibility, normally controlled by a rota system, for the diagnosis and treatment of patients in hospital with emergency conditions that require them to be immediately available for recall; and $(c)$ are expected to be recalled to hospital in emergency at an average rate of two or more times during a working week.

Table II sets out the payments to hospital doctors classified as regular or essential users. There is no reason why doctors who meet the new criteria should not have such classifications backdated to 1 April 1980 . 
TABLE II-Payments for regular or essential users from 1 April 1980

\begin{tabular}{lcccc}
\hline & $501-1000 \mathrm{cc}$ & $1001-1500 \mathrm{cc}$ & $1501-2000 \mathrm{cc}$ & Over 2000 cc \\
\hline Lump sum & $£ 266$ & $£ 310$ & $£ 395$ & $£ 395$ \\
Rate per mile & $12.9 \mathrm{p}$ & $14.5 \mathrm{p}$ & $17.7 \mathrm{p}$ & $19.5 \mathrm{p}$ \\
up to 9000 & $6.9 \mathrm{p}$ & $7.6 \mathrm{p}$ & $8.9 \mathrm{p}$ & $10.8 \mathrm{p}$ \\
\hline
\end{tabular}

If there is a disagreement between a hospital doctor and his employing authority over classification as a regular or essential user there is a special appeals mechanism under which the employing authority will refer the matter to the DHSS, who will consult the profession's representatives.

The new rates were not announced until 20 December 1980, but they are backdated in England and Wales to 1 April 1980; in Scotland the starting date was 20 December 1980. Hospital doctors who have claimed any milage payments since that time should ensure that they receive any supplementary payments now due to them. A few individuals with a high annual milage may find that the new rates are initially not so advantageous as the standard rate payments under the previous scheme. In that case they may continue to be paid on the old rates until such time as it becomes advantageous for them to change.

\section{Loans for car purchase}

The new rules contain advantageous provisions for loans for car purchase for doctors who qualify for the first time as regular or essential car users in the NHS. They are entitled to a loan at $2 \frac{1}{2} \%$ flat rate of interest, provided that the request for the loan is made within three months of such classification or of taking up the post (whichever is the later). This provision does not apply to doctors who become regular or essential users from 1 April 1980 simply as a result of the new rules. But those who qualified since that date as regular or essential users either because of taking up a new post or because of a change in their duties may apply for a low-interest loan; they should do so by $20 \mathrm{March}$ 1981-three months from the date of the circular. The maximum loan available is $£ 2750$ and is repayable over a period of up to five years.

In some cases doctors may be offered a suitable Crown car; in those circumstances a low-interest loan will not be granted even if the doctor refuses to accept the vehicle. In determining whether a Crown car is "suitable" the authority may take various factors into account such as the total official milage, reliability, the need to carry heavy or bulky equipment, and local road conditions, etc. The DHSS has accepted that the suitability question is one that may be the subject of appeal under the Whitley Council appeals procedure.

Loans for car purchase at the Treasury rate of interest current at the time the loan is taken out may be granted by the employing authority from time to time to regular or essential users under the same conditions as for the low-interest loans. The minimum period between such loans is three years or 50000 miles (official and private), whichever occurs sooner.

\section{Good deal for the NHS}

Even with these new improved arrangements, the NHS does well out of the fact that most official milage travelled by hospital doctors is in their own vehicles. If the NHS had to provide transport for all the official journeys made by hospital doctors the cost would be far greater-and the implications for the Treasury worrying.

One of the main problems that the profession's negotiators faced was that negotiations on behalf of other NHS staff were being conducted concurrently in another forum. In any future similar negotiations the profession's representatives will want assurances at the outset that their discussions will be completely independent. That was, after all, why doctors left the cumbersome Whitley machinery.

\section{References}

${ }^{1}$ Department of Health and Social Security. Personal transport arrangements. Advance Letter (MD) 5/80. London: DHSS, 1980.

2 Anonymous. $\mathrm{Br} \mathrm{Med} \mathcal{F} 1981$;282:85-6.

\section{Medical professional advisory machinery in Wales-continued from page 754}

member to be represented by an alternate if he is for any reason unable to attend. The working party took note of the fact that community medicine, unlike other specialties, has no specialty subcommittee: they recommend to the Welsh Medical Committee that such a subcommittee be established, to represent not only community physicians, but also clinical medical officers working in the community health field.

Reviewing the membership further, the working party consider that two representatives of the Welsh National School of Medicine are a necessary and desirable part of the committee.

They reviewed the relationship between the Welsh Medical Committee and other national medical and related committees. It is their view that although the Welsh Medical Committee must be the main policy-forming committee in medical matters, it should not attempt to take over the functions of committees working in a narrower field either with an executive role, or advising on matters which essentially implement broad policy. The Welsh Medical Committee should not, therefore, attempt to take over the functions of the Welsh Manpower Committee, or the Welsh Medical Postgraduate Education Committee. At the same time it is very desirable that these committees be aware of and to an extent be guided by, the views of the Welsh
Medical Committee and its subcommittees: it is considered that this objective is satisfactorily attained by the present constitution whereby the chairmen of these committees are members of the Welsh Medical Committee. A similar argument applies to the Welsh Committee for Locally Organised Research, and the membership of the chairman of that committee on the Welsh Medical Committee should continue.

The working party believe that links between the Welsh Medical Committee and the Welsh Scientific Advisory Committee should be close: the arrangement, whereby two representatives of the Welsh Medical Committee are nominated to serve on the Welsh Scientific Advisory Committee, should continue.

The working party wish to emphasise very strongly the importance of the Welsh Medical Committee as a major source of advice on strategic planning of the Health Service in Wales. On medical matters its advice must be pre-eminent. It therefore wishes to stress the importance of the committee being consulted at early stages of the preparations of any strategic plans for the Health Service, so that the committee can influence 